\title{
UM VERNIZ DE CIVILIZAÇÃO: A SOCIEDADE RECIFENSE VISTA POR VAUTHIER
}

Virgínia Pitta Pontual, Juliana Melo Pereira, Dirceu Cadena de Melo Filho, Laura Nobre Alecrim

Programa de Pós-graduação em Desenvolvimento Urbano, Universidade Federal de Pernambuco

\section{Resumo}

O artigo trata da visão do engenheiro francês Louis-Léger Vauthier sobre a sociedade recifense do século XIX. Para tal, foram utilizados os relatos que o mesmo deixou registrados em dois momentos diferentes: seu Diário íntimo, escrito durante sua estadia no Recife (1940-46), e as Cartas sobre as casas de residências no Brasil, escritas na França. A visão de mundo do engenheiro é guiada por suas concepções fourieristas e suas impressões sobre a sociedade recifense são incrustadas de espanto, sobre o que, no olhar dele, era uma "barbárie com verniz de civilização". A partir dessa impressões o que se buscou foi verificar se seus relatos eram compatíveis com outras visões de sua época.

Palavras-chave: Vauthier - sociedade recifense - século XIX

\section{Abstract}

The article deals with the vision of the French engineer Louis- Léger Vauthier on the nineteenth century society of Recife. We used the reports that he has written down in two different moments: his personal diary, written during his stay in Recife (1940-46), and the Letters on the homes of households in Brazil, written in France. The worldview of the engineer was guided by his Fourierists conceptions and his views on society of Recife are embedded in amazement, about what, in his eye, was a "veneer of civilization with barbarism." From this impression the idea was to check whether his registers were consistent with other views of his time.

Keywords: Vauthier - society of Recife - nineteenth century 


\section{Introdução}

Sair da França e aportar no Brasil sem conhecer muitas pessoas hoje pode ser uma aventura. Embarcar em um navio, cruzar o Atlântico, e aportar em 1840 numa ex-colônia portuguesa talvez fosse uma loucura. Essa foi a experiência que o engenheiro francês Louis-Léger Vauthier deixou registrada em seu Diário íntimo e nas Cartas sobre as residências no Brasil, a partir da qual foi apreendida a sociedade recifense do século XIX. Procuramos identificar enunciados, permanências e rupturas, a fim de entender se os relatos de Vauthier sobre esta sociedade condiziam com outros da mesma época. Cabe advertir o leitor que as Cartas e o Diário mostram o autor em dois momentos diferentes: o Vauthier do Diário escreve no fervor dos acontecimentos, em tom confessional, descreve suas impressões do cotidiano; o Vauthier das Cartas se distancia do objeto analisado e com rigor descreve o Brasil e suas construções de forma ampla e cuidadosa. Neste texto, optou-se por utilizar mais o Diário por suas observações mais diretas sobre a sociedade. As repetidas vezes em que Vauthier se refere à sociedade recifense como "barbárie, incrustada na selvageria, e malmaquiada por um verniz de civilização" foram o ponto de partida para o debate que se pretende aqui estabelecer.

\section{Entre o socialismo e a engenharia: as influências da visão de mundo de Louis- Léger Vauthier}

Um socialista romântico e um engenheiro apaixonado. As palavras de Antônio Dimas (2010) definem bem os dois principais pontos que, aparentemente, guiaram a visão de mundo do francês Louis-Léger Vauthier. Um panorama, ainda que - nos limites deste artigo - breve, sobre a formação do engenheiro e o contexto intelectual em que ele se insere nos ajuda a compreender o olhar de um estrangeiro, que deixa um dos países mais adiantado da Europa, para aportar num país recém-independente ainda repleto de traços coloniais.

Filho de engenheiro, Vauthier formou-se na École Polythecnique de Paris e especializou-se na École des Ponts et Chaussés, em ambas escolas foi estimulado a ter uma formação múltipla, onde teoria e prática se cruzavam na busca de soluções diárias de infra-estrutura. De acordo com Lucio (2000), o Corp des Ponts et Chaussés (que data de 1716-1720) foi a primeira organização de um corpo de engenheiros não 
militar, que tinha como responsabilidade a administração, construção e controle das obras públicas no território francês. Em 1775, foi criada a École Royal de Pont et Chaussés, para formar engenheiros do Estado. Lucio (2000: 144) ainda aponta uma clara definição do ensino nesta escola: "aplicação dos princípios da física e da matemática à arte de construir e conservar as obras, as técnicas e a prática da execução; a arte de redigir orçamentos e os detalhes estimativos das obras a executar". A Pont et Chaussés diferenciava-se da Academia Real de Arquitetura principalmente pela prática profissional, em um momento em que as cidades já davam sinal de crescimento acelerado e que a demanda por infra-estrutura (construção de galpões, pontes, estradas, etc.) não era considerada pelos arquitetos, essa diferença foi crucial.

A École Polythecnique de Paris criada em 1794, durante a Revolução Francesa, teve importância que foi muito além da instituição e até da própria França, como coloca Santos Filho (2010) e Chatiz (2010). Criada para formar um corpo de engenheiro desvinculados do Antigo Regime e por uma elite intelectual reunida em torno de Gaspar Monge (cientista e político, criador da geometria descritiva), a Polythecnique tinha como princípio a aplicação de conhecimentos teóricos à questões práticas (CHATIZ, 2010) e, ao contrário das escolas de engenharia militar, propunhase a "compartilhar publicamente de seus resultados sem conhecimentos secretos". Era missão da Polythecnique treinar os engenheiros, disseminar pessoas esclarecidas na sociedade civil e despertar talentos que fizessem a ciência avançar (SANTOS FILHO, 2010: 43). Os alunos desta escola eram instruídos durante três anos com conhecimentos globais (Geometria Descritiva, Arquitetura, Desenho, Física, Química, etc), no término deste período os alunos formados poderiam trabalhar nos serviços públicos, ou se especializar nas Escolas de Aplicação, de Engenharia Militar ou na de Pontes e Calçadas, como preferiu Vauthier. Lucio (2000) enfatiza o saber enciclopédico de Vauthier e dos engenheiros que compartilharam de sua mesma formação na França, que tinham conhecimento sobre diversas disciplinas e debatiam sobre os mais variados temas.

O século XIX foi marcado, em toda Europa, por profundas transformações nas cidades, submetidas a um súbito crescimento populacional que trouxe novas demandas. O inchaço das cidades e as péssimas condições de vida da população despertaram a atenção não só dos engenheiros, aptos a oferecer novas soluções, mas também de teóricos sociais que buscavam explicações e alternativas ao novo mundo capitalista e industrial. Entre estes teóricos estavam os socialistas utópicos, com os 
quais Vauthier demonstrou, através de suas anotações e prática profissional, ter grande afinidade. Entre os livros lidos e analisados pelo engenheiro em seu diário estão Julles Lechevalier, Sant-Simon, Robert Owen e Charles Fourier. Este último, era o autor mais difundido na École des Ponts et Chaussés e guiou, inclusive, a forma de Vauthier enxergar o mundo ao seu redor.

Precursor do socialismo utópico, o francês Charles Fourier deixou um dos mais completos e detalhados modelos de organização social: a falange (ou falanstério). Partindo de uma crítica ferrenha à sociedade contemporânea e a sua economia, Fourier construiu sua "Teoria dos quatro movimentos" em que antes de atingir a harmonia, a sociedade passaria por quatro etapas sucessivas: a selvageria, a barbárie, o patriarcado e a civilização.

A aproximação de Vauthier com as teorias socialistas aparece em diversos trechos de seu diário, de forma que Lucio (2000) chega a concluir que entre os motivos que trouxeram o engenheiro francês ao Brasil - além do desejo por aventura e fortuna - estavam os estudos para a implantação de um possível falanstério.

Nossa leitura sobre os escritos de Vauthier não nos permite chegar a tal afirmação, mas certamente não podemos negar o papel do engenheiro na propagação das idéias socialistas no Brasil.

Ao aportar em Pernambuco, Vauthier se depara com um quadro bem diferente do que deixara na França. O Brasil, com mais de $75 \%$ de população analfabeta, contrastava-se com a França, que desde 1833, instituíra o ensino primário gratuito obrigatório. Apesar de não acreditar que as elites pernambucanas formavam um conjunto intelectual significativo, Vauthier relaciona-se com parte da elite pernambucana, chegando com alguns a compartilhar os ideários progressistas. Santos Filho (2010) destaca o caso de Antônio Pedro de Figueiredo, editor da revista $O$ Progresso, que já continha em seu primeiro número um texto do engenheiro.

A aproximação de Vauthier com as elites pernambucanas é um fato bastante questionado, bem como a relação do socialista com a escravidão. Marzon (2000) considera ambígua a prática de Vauthier, argumenta que, em alguns pontos, 0 exercício de sua profissão não era coerente com seu discurso socialista - cita como exemplo a construção de estradas que favoreceriam grandes proprietários de açúcar. Já Mérian (2000: 157), não atribui ambigüidade à prática de Vauthier, visto que este não seria um militante, mas sim "um reformista que acreditava na força das idéias". 


\section{Cabeça sem corpo $^{1}$ : a cidade do Recife em 1840}

Numa época em que navegar era preciso, Vauthier se lança aos mares em 24 de julho de 1840 com destino ao incerto em busca de uma realização pessoal composta de fortuna, sucesso, reconhecimento, novas experiências e ideologias. Recife era o destino herdado pela vida onde as incertezas seriam curadas e os sonhos conquistados. Mas como era a Cidade dos trópicos em 1840? O que acontecia naquela cidade tão distante, em todos os aspectos, das cidades francesas?

O escravo detinha um papel fundamental na sociedade brasileira do século XIX, servindo como força de trabalho nos engenhos de açúcar pelo interior da nação, ou realizando trabalhos braçais e serviços indesejáveis nas grandes cidades. Tratados de forma ambígua, os escravos eram cativos, subjugados a trabalhos insalubres, sofrendo com penas severas em função de faltas brandas e, ao mesmo tempo, mantinham relações intimas com a população livre. Em Casa Grande e Senzala, Freyre (2003) relata de forma singular a adoção de alguns escravos que participavam da vida familiar ao ponto de receber o nome da família acolhedora. As gravuras de Debret ${ }^{2}$ (FIGURA 1), que fez parte da Missão Francesa no Brasil, também mostram uma relação de proximidade entre os negros e as famílias proprietárias.

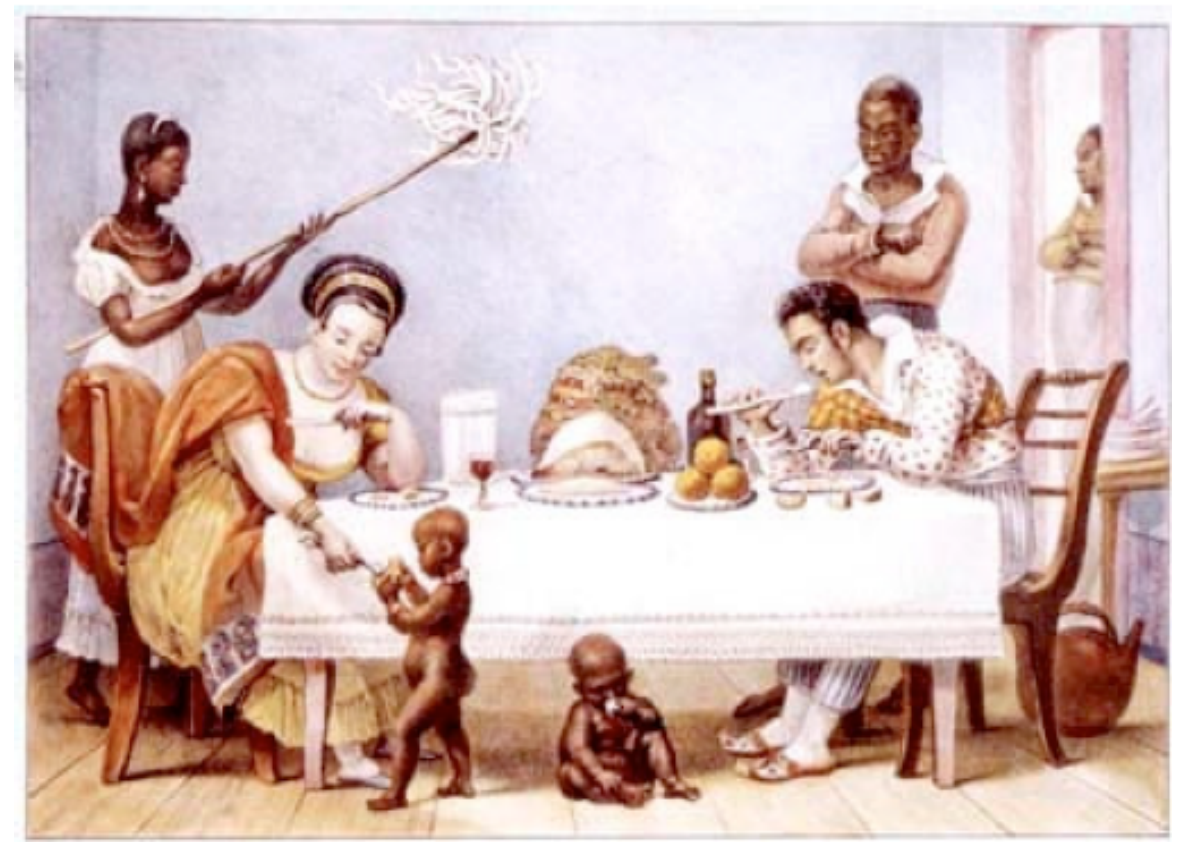

Figura 1: Interior de uma casa de família brasileira no século XIX.

\footnotetext{
1 "Cabeça sem corpo. Gente a qual é preciso dar comida na boca."(VAUTHIER, 2010:135)

2 Jean-Baptiste Debret foi um pintor e desenhista francês, integrou a Missão Francesa no Brasil e permaneceu aqui durante 15 anos.
} 
Fonte: Debret, 1993

Se aparentemente nos arredores do Recife a relação dos escravos com os homens livres seguia um caminho harmonioso, alguns relatos de visitantes mostram como a sociedade urbana tratava sua principal força de trabalho no século XIX:

Estava pobremente abastecido, devido às circunstâncias da cidade, que faziam com que a maior parte dos possuidores de novos escravos os conservassem bem fechados nos depoimentos. Contudo cerca de cinqüenta jovens criaturas, rapazes e moças, com todas as aparências da melancolia e da penúria, conseqüência da alimentação escassa e do longo isolamento em lugares doentes, estavam sentados e deitados na rua, no meio dos mais imundos animais (GRAHAM,1990:134)

Talvez as práticas relatadas por Maria Graham³ causem desconforto a um leitor do século XXI, porém é importante lembrar que àquela época uma visão pautada na igualdade racial não existia no Recife e, possivelmente, em nenhuma cidade do Brasil. Desta forma, não é de se estranhar que negros fossem tratados com indiferenças, mesmo pelas elites intelectuais da época.

Outra característica típica da sociedade recifense pode ser vista nas festas promovidas pelas elites. Como apresenta Lucio (2000), nos saraus das pessoas nobres se falava francês, servia sucos de frutos da época em taças de cristal e as danças que embalavam os flertes proibidos entre jovens damas e senhores eram as mesmas encontradas em qualquer salão da Europa. A alta sociedade recifense estava sempre com a cabeça voltada para a Europa, mas com o corpo preso as relações culturais do Brasil. Desta forma era normal para o alto escalão ir estudar na França ou Portugal onde se adquiria conhecimento teórico sobre diversas ações, e, ao retornar ao Brasil, manter certas tendências conservadoras.

"A abertura do país ao comércio exterior e o conseqüente contato com a cultura européia fez com que essas elites vissem as cidades brasileiras como "antiquadas" e "impróprias"" (ZANCHETI, 1989: 77) e por isso diversas tentativas de construir um novo Recife foram empreendidas. A principal talvez tenha sido colocada em prática por Francisco do Rêgo Barro, conhecido posteriormente como o Conde da Boa Vista ${ }^{4}$. As mudanças empreendidas alteraram a dinâmica sócio-espacial não apenas da cidade, mas as formas de divertimento (SANTOS, 2009) e os acessos às áreas rurais. Em sua

\footnotetext{
${ }_{3}$ Maria Dundas Graham Callcott foi uma escritora inglesa que esteve de passagem no Brasil entre 1821 e 1823 e deixou registradas as suas impressões sobres diversas cidades do Brasil. ${ }^{4}$ Filho de donos de engenho, logo se interessou pela carreira militar e política e, após retornar dos estudos superiores em Paris, empreendeu diversas ações urbanas na sociedade recifense.
} 
gestão foram feitas estradas, pontes, penitenciárias, palácios e teatros.

O Teatro de Santa Isabel, obra iniciada no governo de Francisco do Rêgo Barros, projetado originalmente por Vauthier, exemplifica bem como as mudanças empreendidas pelo governante alteraram os hábitos das elites locais. Ao mesmo tempo em que funcionava como local de exibição e sociabilidade das altas castas, era o local possível de esquecer as danças, músicas, festas e comidas produzidas nas senzalas (FIGURA 2).

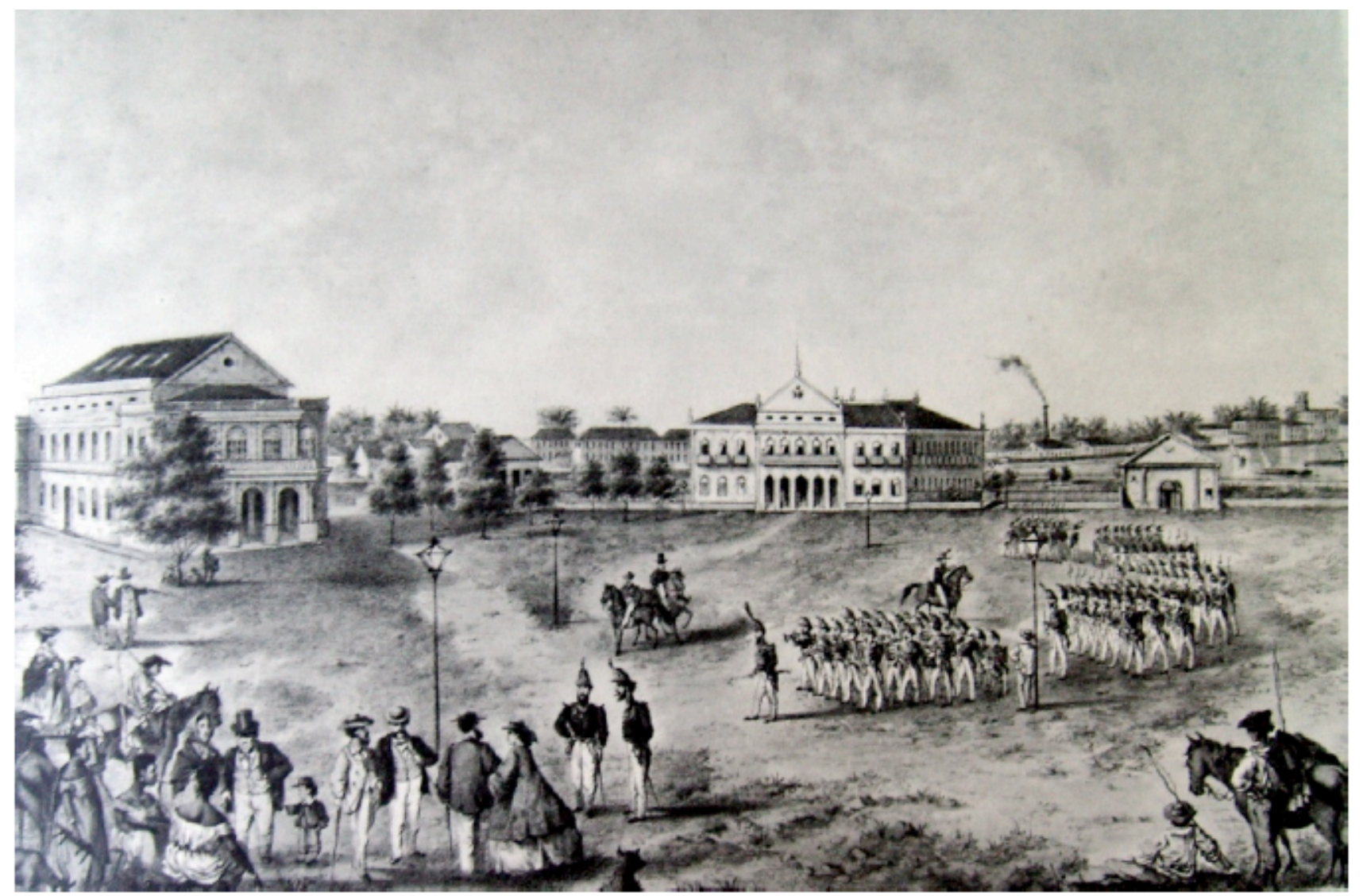

Figura 2: Campo das Princesas, à esquerda o Teatro Santa Izabel (projeto de Vauthier), ao centro o Palácio do Governo da Província. Recife, século XIX.

Fonte: Schlappriz, 1863.

Com relação as mulheres, é interessante notar que a tradicional reclusão observada por viajantes europeus não se aplicava às negras, forras e livres pobres. Assim, era comum encontrar mulheres nas ruas trabalhando em vendas ou vagando em busca de exercer algum ofício, dominando os perigos das cidades (SILVA, 2005). Sobre o assunto, o viajante francês Tollenare ${ }^{5}$ anota em 1817:

${ }^{5}$ L.F. Tollenare foi um viajante francês que esteve na cidade do Recife entre 1816 e 1817 , suas impressões foram registradas em Notas dominicais: tomadas durante uma viagem em 
negras percorrem as ruas oferecendo à venda lenços e outras fazendas que trazem em cestos sobre a cabeça (...). Não se vê absolutamente mulheres brancas na rua.Um pequeno mercado junto de uma igreja oferece à minha vista montões de raízes de mandioca, bananas, ananases, cajus, mangas e laranjas. As vendedeiras, mui sucintamente vestidas, algumas de cachimbo ao queixo, preparam grosseiros manjares para o povo (...) (TOLLENARE 1978, p.58 apud SILVA, 2005, p.4)

Outra característica do Recife do século XIX era a facilidade com que crimes ocorriam. Interesses políticos, financeiros ou simples casos de amor seriam motivos suficientes para se tirar a vida de outra pessoa. Como mostra o Conde de Suzannet ${ }^{6}$ (1954:208 apud LUCIO, 2000:55):

os assassinos são mandados por homens ricos que oferecem asilo e proteção aos que eles empregam, a fim de se fazerem respeitados e temidos pelos seus vizinhos e outros proprietários (...)

Este era o cenário que Vauthier encontrou na cidade do Recife ao chegar em 8 de setembro de 1840. Uma cidade que exala escravos, predominantemente agrária, com crimes banais e que, apesar de independente, ainda mantinha fortes resquícios dos tempos coloniais. A cidade, ao mesmo tempo em que buscava a imagem de uma cidade moderna, não se libertava das amarras tradicionais (FIGURA 3).

Portugal e no Brasil em 1816, 1817 e 1818. Bahia: Progresso, 1956.

${ }^{6}$ Conde Suzannet foi um visitante francês que esteve no Brasil por volta de 1840 . 


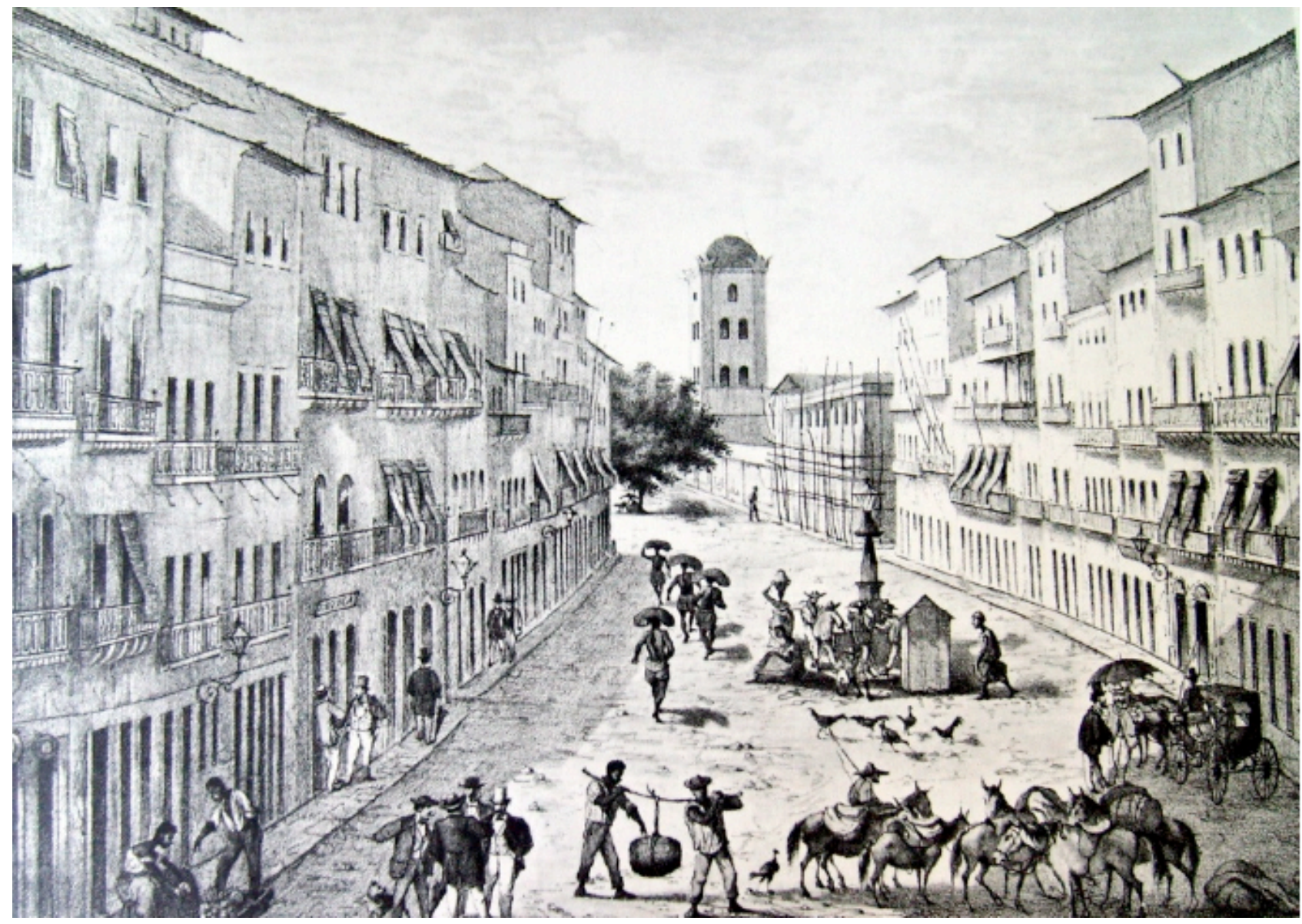

Figura 3: Rua da Cruz (atual Rua do Bom Jesus), Recife, séc. XIX. Observar os escravos, comércio, a busca por água na fonte pública.

Fonte: Schlappriz, 1863.

As palavras de Vauthier nos revelam a visão de um fourierista que acredita que a sociedade marcha para estados melhores até um dia, talvez alcançar a harmonia. No entanto, também revela a visão de um jovem politécnico que por trás dos anseios de progresso, esconde um certo olhar colonizador. De acordo com Gallo (2010: 43), Vauthier "munido de um modelo antecipadamente formado, lia o país através dos olhos do europeu civilizado". Mas, se a obra é um diário, logo, de caráter pessoal, por que esse ímpeto colonizador de Vauthier não é diretamente revelado? Porque nem para os próprios politécnicos esta era uma questão esclarecida, como mostrou Filho (2010: 45):

O teste prático dos primeiros alunos formados na Escola Politécnica foi a grande expedição francesa ao Egito, iniciada em 1797 e que além de ter obviamente um caráter militar, possuía uma dimensão científica muito pronunciada (...) A comissão começou a trabalhar logo depois do desembarque no Cairo das tropas francesas chefiadas por Napoleão, Monge e Fourier. Essa missão pode, sem dúvida, ser vista na perspectiva do 
avassalador ímpeto imperialista das metrópoles européias no século XIX. De acordo com a visão de Monge, no entanto, sua principal função seria o progresso e a propagação de idéias iluministas no Egito, e é bem possível que os jovens egressos da Politécnica acreditassem sinceramente na nobreza desses ideais, para além de uma condição puramente de agentes do colonialismo francês.

Em alguns momentos, Vauthier se mostra desacreditado com a possibilidade de desenvolvimento desta sociedade: "Mesmo assim, apesar dessa vida simples, sua preguiça e imprevidência são tais, que o problema da existência dessa gente parece insolúvel" (VAUTHIER, 2010: 103). A todo o momento, o engenheiro insiste na preguiça dos brasileiros, que para ele é responsável por grande parte do atraso, pois como fourierista que era, apostava no prazer pelo trabalho e na ciência para alcançar o progresso e "instaurar na terra certa ordem e regularidade e de se estabelecer o sistema que torne a maioria feliz" (op. Cit.:75)

Em Recife, o Vauthier fica decepcionado com o intelecto do povo, do Presidente da Província, "esperava inteligência mais fina" (op. Cit.:84), assim como da maior parte das pessoas com que vem a conviver. O engenheiro sente falta de ter com quem conversar, acha impossível falar sobre negócios com o Presidente e que "acharia agradável ter alguns minutos de uma conversação alegre, brincalhona, para poder trocar idéias - mesmo superficiais, mas idéias. Idéias! Quem as tem neste pobre país?" (op. Cit.:148-149) Tamanho era o seu isolamento que, ao saber que Felipe Neto $^{7}$ era fourierista, segundo o seu diário, pediu licença ao presidente para ir visitálo, pois "as idéias inovadoras poderiam interessá-lo" (op. Cit.:226).

Não é que o Recife desconhecesse as idéias que vinham da Europa. Segundo Poncioni (2010:351) a presença de livros franceses era forte no Brasil desde meados do século XIX e existia um mercado, embora restrito, consumidor de livros na província. Freyre (apud Poncioni, 2010:351) insiste na influência dos livros franceses em tornar o Recife daquela época em um grande centro de atividades políticas e sociais. O Recife queria ser modernizar. Só que para Vauthier isso consistia em uma vaidade oca (VAUTHIER, 2010:109), que apesar da sociedade desejar esta evolução, nada faz para isso, e vive de farsas.

Não pensam, estou certo, nem a quarta parte de uma única palavra que escrevem. Que povo de farsas e de aparências exageradas! É uma terra admiravelmente preparada para a cultura de idéias políticas. Por isso brotam tantas! Isso me enjoa. Quando falam de seu país, tudo o que lhe sucede de mal, atribuem a falta de patriotismo. Sim, de fato, o patriotismo é nobre e

\footnotetext{
${ }^{7}$ Segundo Poncioni (2010) Felipe Neto participou da Revolução Praieira em 1848.
} 
bom, como todos os sentimentos nos homens que derivam do uniteísmo, mas será cabível infelizes, em meio de sua desordem e de sua miséria...? Trabalhem para melhorar sua posição. Trabalhem! Movam os braços e a inteligência e depois virá o patriotismo. Eu gostaria mesmo que alguém pedisse a um desses vadios que tanto falam de falta de patriotismo que carregasse uma mira e ajudasse a fazer um nivelamento. Diria logo que não é nem criado nem cativo, que é livre e não nasceu para carregar coisa alguma. Pobre gente! (op.Cit.: 159-160)

Poncioni (2010: 350) afirma que, adepto ao fourrierismo, Vauthier é do grupo majoritário dos propagadores, que acreditam que a principal tarefa a realizar é a difusão do ideário fourierista, por meio da leitura e da propaganda o que ele "não é um revolucionário; quer uma transformação progressiva da sociedade." De fato, é possível perceber a vontade que o engenheiro tem em discutir estas idéias, e a dificuldade que tem em encontrar com que discuti-las desde quando estava a caminho de Recife.

Há em mim um desejo imperioso, uma viva necessidade de falar às vezes dessas coisas elevadas que ainda hoje a ciência pressente mais do que explica. Mas bem raras que têm idênticas aspirações e desejos. Tenho então de refletir sozinho, - porém o trabalho solitário do pensamento me é extremamente penoso. As idéias que não posso transmitir perdem para mim todo o encanto (VAUTHIER, 2010:70)

Diante deste contexto, Vauthier se empenha em sua função de propagador, colocando livros a venda ou mesmo emprestando para aqueles que não podiam comprar (PONCIONI, 2010: 352), e também pelo grande número de assinaturas que consegue para as revistas La Phalange, La Démocratie e O socialista da Província do Rio de Janeiro. O último ano de seu diário, as poucas anotações que aparecem se referem a distribuição desses volumes. Vauthier pode não ter entrado em choque com as elites locais, mas foi através de seus livros, revistas, artigos e discussões que encontrou a melhor forma de disseminar as idéias socialistas, afinal, era esta a essência do fourierismo: "a revolução pacífica, a reforma, a procura de uma nova ordem econômica e social, baseada na harmonia e na concórdia" (MÉRIAN, 2000: 157).

A relação de Vauthier com a escravidão no Brasil ainda é uma lacuna. Se em vários momentos ele se declara, em seu diário, horrorizado com o tratamento concedido aos escravos, poucas foram as vezes em que fez algo para aliviar as condições dessa parcela da população ${ }^{8}$, o que é de se admirar quando consideramos

${ }^{8}$ Quando Vauthier deixa o Recife em 1846 ele cita a existência de uma possível escrava, aparentemente uma babá de seu filho. 
suas filiações socialistas utópicas. Apesar de aceitar o trabalho escravo como parte do sistema produtivo, Vauthier não concorda com o tratamento que muitas vezes foi dado aos negros, como é possível perceber no relato sobre a reação de Madame Sarmento a uma negra que Ihe tinha roubado:

Madame Sarmento nos contou que como sua negrinha the tinha roubado seis vinténs, ela amarrou-lhe as mãos e deu-lhe umas boas chicotadas!!! Levantando- Ihe a roupa!!! Sem nenhum constrangimento!!! Diante dos filhos!!! O mais velho deles observou que o posterior da negrinha não era mais bonito do que o de um cavalo, quando levanta a cauda. Qualquer pessoa poderia chegar a praticar coisas semelhantes num momento de excitação e envergonhar-se delas depois, mas contá-las... Que mulher! Que alma! (VAUTHIER, 2010:132)

Essa postura, aparentemente contraditória, não era exclusiva de Vauthier, mas também à outros contemporâneos que partilhavam das mesmas idéias. Mérian (2010) e Poncini (2010) destacam o fato dos principais jornais difusores do ideário socialista no país - O Socialista e O Progresso - ignorarem o problema social da escravidão. Supomos que, neste momento, a escravidão era tida como uma condição inerente a existência e funcionamento da sociedade brasileira, que não cabia aos fourrieristas (pelo menos aos olhos deles) discutir.

Vauthier também estranha com a relação, tão íntima, que se dá entre senhores e escravos, nessa relação tão comum, que quando resultam filhos de relações de senhores e escravas, estes são aceitos como parte da família.

Ele visitou Madame Sarmento que, a despeito de seus princípios religiosos, toma dispositivos para comprar uma negrinha, servente de um convento de freiras onde se dá mal, porque ali não pode ver homens. Pois bem! Quando elas tem filhos, os donos ficam com eles: é o costume do país. Costume do país! Que querem mais? - Madame Sarmento acha que isso lhe convém. (VAUTHIER, 2010:95)

Se não identificamos na prática de Vauthier tentativas de amenizar as chagas da escravidão, durante o período em que chefiou a Repartição de Obras Públicas de Pernambuco (1840-46) exigiu melhorias nas condições dos trabalhadores (vestimentas, alimentação, abrigo). Lúcio (2000) destaca que, independente de serem escravos ou empregados livres, Vauthier considerava-os homens e exigia que fossem tratados como tal. A autora ainda coloca que Vauthier insistiu em extinguir o trabalho escravo da ROP baseado em dois principais argumentos: dar serviço à multidão desempregada e melhorar o nível técnico dos trabalhadores, e, conseqüentemente a 
qualidade das obras executadas.

As mulheres brasileiras são descritas por Vauthier, em seu diário, em tom crítico, como quase tudo no país. Em ocasião, no Baile da Sociedade Apolínea declara: "Sala pouco elegante. Mulheres do mesmo nível." (VAUTHIER, 2010:91). Porém, é nas cartas que descrevem com pormenores a organização espacial das casas no Brasil que se percebe claramente o papel da mulher em uma sociedade patriarcal do século XIX. Todas as casas, das urbanas às rurais, têm em comum não expor suas mulheres, para Vauthier "a mulher no Brasil, é mantida sob uma reserva extrema, em uma clausura quase absoluta" (VAUTHIER, 1943:137). Uma contradição, ao se considerar que neste momento a sociedade recifense tentava se mostrar moderna e civilizada. Como poderia uma sociedade avançada conceder semelhante tratamento às mulheres?

Sobre a reclusão das mulheres da alta sociedade, Vauthier observa durante a visita ao Engenho Camaragibe:

Fomos levados a um salão que serve ao dono da casa de gabinete de trabalho e que não revelava nenhum indício de presença feminina. [...] Enfim, depois de duas cruéis horas de espera, fomos chamados à sala de jantar. Eu tinha avistado, pelas portas entreabertas, as costas de uma mulher, evidentemente a dona da casa. Esperava encontrá-la na sala de jantar. Nem sombra da mulher (VAUTHIER, 2010:141)

Aparentemente essa visão de Vauthier sobre o mundo feminino, expressa em seu diário intimo, representa um olhar do homem da alta sociedade. Neste ponto, as observações são voltadas para os atributos físicos femininos, e da possibilidade de futuros relacionamentos sexuais. Enquanto que nas cartas, a visão volta para o papel da mulher na sociedade, onde Vauthier nota a presença feminina nas ruas da cidade:

negras, trazendo à cabeça um tabuleiro (bandeja de madeira com bordos) cobertos de pilhas de bolinho e compoteiras, com doces de frutas, percorrem à rua buscando freguesia e instalam-se afinal em alguma encruzilhada bem freqüentada, onde, como um pirilampo em um arbusto, acenderão uma pequena lanterna sobre o cesto pra indicar a sua presença (VAUTHIER, 1943:179).

A respeito da violência na cidade, Vauthier se mostrou de início incrédulo com os avisos de Monsieur Thérbege, um médico francês, que Ihe antecipou detalhes sobre o Brasil: "Detalhes sobre o país, em que não acreditei. Segundo ele, aqui matam as pessoas como moscas. Esqueci de lhe perguntar quantas vezes ele foi morto." (VAUTHIER, 2010:91). Porém, ao longo de sua estadia no Recife, com os constantes relatos sobre assassinatos por motivos de toda ordem principalmente interesses 
políticos, Vauthier muda de opinião e passa a temer por sua vida, inclusive adquirindo armas para defesa pessoal.

Antes de vê-lo, tinha tido alguma desconfiança. Ocorreu-me a idéia de levar as pistolas. Comprei os coldres expressamente com esse fim. Levá-los, entretanto, seria mostrar muito claramente minha desconfiança. Preferi deixálos. Levei apenas uma faca de ponta no bolso. (VAUTHIER, 2010:167)

A estadia de Vauthier no Recife foi uma constante surpresa, como pode ser observado em seu diário intimo. Ao final de cada dia, onde o jovem francês anotava suas profundas observações sobre a sociedade ao seu redor, ele se apresentava cada vez mais perplexo com sua constatação de que o povo se encontrava em uma barbárie. Estremo conhecedor da cidade do Recife e dos arredores, para onde realizou constantes viagens (FIGURA 4), os relatos de Vauthier mostram um engenheiro não apenas preocupado com as limitações estruturais do Brasil, mas em busca de alterações sociais e de melhorias nas condições humanas.



Figura 4: Ilustração indicativa dos locais citados por Vauthier em seu diário. Fonte: Juliana Pereira, Magna Milfont e Virginia Pontual, 2009 


\section{Conclusão}

Vauthier representava o resultado de um contexto peculiar. Tendo adquirido amplo conhecimento social juntamente com as noções profundas da engenharia na École Polythecnique de Paris, desenvolveu ações numa cidade voltada para o futuro, mas com práticas tradicionais. Apesar de o Recife ser uma das mais importantes cidades do Brasil independente, o local mantinha atrasos de uma colônia. Vauthier apresentou estas características ao longo de seu diário: Escravidão, violência, reclusão da mulher eram temas recorrentes.

Seus relatos apresentam um estrangeiro insatisfeito com as condições em que se encontrava a sociedade. O Recife observado por Vauthier não era um único. Como foi buscou apresentar ao longo do texto, outros visitantes também compartilharam de seu espanto. Tanto os franceses Tollenare, Conde de Suzannet e Debret, quanto a inglesa Maria Graham deixaram observações semelhantes sobre a sociedade recifense.

Vauthier deixou marcas profundas no Recife que vão além do campo da engenharia. Ele reformou não apenas as formas da cidade, mas foi um dos principais propagadores dos novos ideais que viriam a mudar o mundo no século $X X$.

\section{Referências}

CHATIZ, Konstantinos. Les ingénieurs du progrès: la figure de l'ingénieur-savant dans la France des anées 1820-1860. In:PONCIONI, C.; PONTUAL, V. Un ingénieur du progrés: Louis-Léger Vauthier entre la France et le Brésil. Paris: Michel Houdiard éditeur, 2010.

CHOAY, Françoise. O urbanismo. Utopias e realidades, uma antologia. São Paulo: Editora Perspectiva, 2005.

DEBRET, J.B. O Brasil de Debret. Belo Horizonte:Vila Rica Editora Ltda, 1993.

DIMAS, Antônio. Um socialista romântico e um engenheiro apaixonado. In:PONCIONI, C.; PONTUAL, V. Un ingénieur du progrés: Louis-Léger Vauthier entre la France et le Brésil. Paris: Michel Houdiard éditeur, 2010.

FERREZ, Gilberto. O Álbum de Luís Schlappriz: Memória de Pernambuco, álbum para os amigos das artes, 1863. Recife: Fundação de Cultura da Cidade do Recife, 1981.

FILHO, Gildo M.S. A Escola Politécnica de Paris, a inspiração republicana e a 
idéia de progresso: Vauthier, a engenharia francesa e brasileira no século XIX. In:PONCIONI, C.; PONTUAL, V. Un ingénieur du progrés: Louis-Léger Vauthier entre la France et le Brésil. Paris: Michel Houdiard éditeur, 2010.

FREYRE, Gilberto. Casa Grande e Senzala: Formação da família brasileira sob o regime da economia patriarcal. São Paulo: Global, 2003.

GALLO, Ivone. As fronteiras do socialismo: Vauthier, Benoît Mure e o socialismo no Brasil. In:PONCIONI, C.; PONTUAL, V. Un ingénieur du progrés: Louis-Léger Vauthier entre la France et le Brésil. Paris: Michel Houdiard éditeur, 2010.

GRAHAM, Maria. Diário de uma Viagem ao Brasil. São Paulo: Editora da Universidade de São Paulo, 1990.

LEONÍDIO, A. As idéias do socialismo utópico no Brasil. Cadernos de história. Mariana: UFOP. v.2, p. 98-117, 2009. Disponível em: <http://www.ichs.ufop.br/cadernosdehistoria/download/CadernosDeHistoria-0808.pdf>, Acesso em 13 jan. 2011.

LUCIO, Silvana Tercila M. P. Pernambuco no século XIX: a herança de Vauthier. Campinas: Dissertação de Mestrado/ PUC/Faculdade de Arquitetura e Urbanismo, 2000.

MARZON, Izabel. Política, engenharia e negócios: a polêmica atuação do engenheiro Vauthier na Repartição de Obras Públicas de Pernambuco (1840-1846). In: PONCIONI, C.; PONTUAL, V. Un ingénieur du progrés: Louis-Léger Vauthier entre la France et le Brésil. Paris: Michel Houdiard éditeur, 2010.

MÉRIAN, Jean-Yves. O socialista da província do Rio de Janeiro e O Progresso. In:PONCIONI, C.; PONTUAL, V. Un ingénieur du progrés: Louis- Léger Vauthier entre la France et le Brésil. Paris: Michel Houdiard éditeur, 2010.

PONCIONI, C.; PONTUAL, V. Un ingénieur du progrés: Louis-Léger Vauthier entre la France et le Brésil. Paris: Michel Houdiard éditeur, 2010.

PONCIONI, C. Pontes e idéias: um engenheiro fourierista francês em Pernambuco. Recife: Cepe, 2010.

QUEIROZ, Maurício V. R. Fourier e o Brasil. Revista História. São Paulo, n. 122, p. 5-15, jan/jul. 1990.

SANTOS, Lídia R. Diferentes Formas de se Divertir: Mudanças no Lazer em Recife de Meados do Século XIX. Recife: Anais do Colóquio Interdisciplinar Pontes e Idéias Louis-Léger Vauthier, Recife, 2009, CDROOM.

SILVA, M. H., Na casa, na rua e no rio: a paisagem do Recife oitocentista pelas vendeiras, domésticas e lavadeiras in MNEME - Revista de Humanidades, v. 7, nr. 15, p.1 - 30, 2005. Disponivel em: <http://www.cerescaico.ufrn.br/mneme/pdf/mneme15/146.pdf>

VAUTHIER, L.L. Casas de residência no Brasil. Revista do SPHAN. Rio de Janeiro, 
n.7, p.125-208, 1943.

VAUTHIER, L.L. Diário íntimo. In: PONCIONI, C. Pontes e idéias: um engenheiro fourierista francês em Pernambuco. Recife: Cepe, 2010.

ZANCHETI, Sílvio. O Estado e a Cidade do Recife: 1822 - 1889. Tese de Doutorado. USP, 1989 